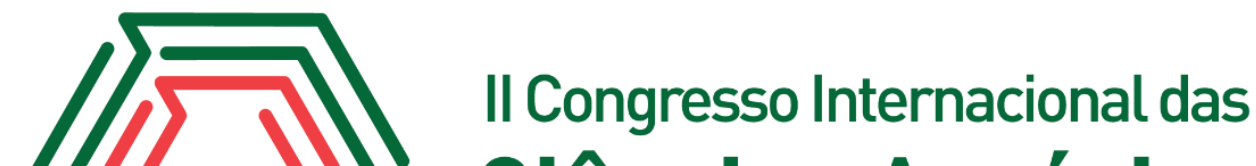 Ciências Agrárias COINTER - PDVAgro 2017
}

\section{INFLUENCIA DA SALINIDADE POR CLORETO DE SÓDIO NA GERMINAÇÃO DE SEMENTES DE Crotalaria juncea $\mathrm{L}$.}

\begin{abstract}
$\underline{B r u n a}$ Marques Felipe $^{1}$; Patricya Lorenna de Brito Rodrigues ${ }^{2}$; Salenilza Pires Almeida ${ }^{3}$;uliana Joice Pereira Lima ${ }^{4}$; Edilza Maria Felipe Vásquez ${ }^{5}$.
\end{abstract}

\section{Introdução}

Originária da Índia, a crotalária (Crotalaria juncea L.) possui alto potencial de produção de biomassa e sua utilização como adubo verde pode promover melhorias nos atributos químicos, físicos e biológicos do solo, tornando-a uma importante opção na recuperação de áreas degradadas (NUNES et al., 2009).

As condições para a germinação nem sempre são adequadas, a água é um fator importante para o início do processo de germinação, a sua participação é decisiva nas reações enzimáticas, na solubilização e na condução de metabólitos, e também como reagente na digestão hidrolítica de tecidos de reserva da semente. Sendo que, potenciais osmóticos muito negativos acabam inibindo o potencial de germinação da grande maioria das culturas cultivadas (NUNES, A. da S. et al., 2009)

A salinidade pode ser citada como o principal fator abiótico que limita o crescimento e a produtividade de plantas. Os efeitos da salinidade nas plantas estão ligados à redução do potencial osmótico do meio e aos efeitos tóxicos, causados por distúrbios metabólicos. Em sementes e plantas os efeitos da salinidade pode causar limitações em todos os estádios de crescimento e desenvolvimento, comprometendo eventos fisiológicos que vão desde a germinação até a produção (PINHEIRO, D.T., 2015).

O objetivo do trabalho foi avaliar o efeito do estresse salino, com diferentes concentrações de $\mathrm{NaCl}$, em sementes de Crotalaria junceae.

\section{Fundamentação Teórica}

\footnotetext{
${ }^{1}$ Agronomia, Universidade Federal do Cariri, brunnamarques40@hotmail.com

${ }^{2}$ Agronomia, Universidade Federal do Cariri, p.lorennabrito@gmail.com

${ }^{4}$ Agronomia, Universidade Federal do Cariri, as.anna.maria@gmail.com

${ }^{5}$ Prof. Dra. em Fitotecnia, Universidade Federal do Cariri julianajoicelima@yahoo.com.br

${ }^{6}$ Prof. Dra. Em Fitotecnia, Universidade Federal do Cariri, edilza.felipe@ufca.edu.br
} 
A explicação mais aceita para a inibição do crescimento pelo sal é a redução do potencial osmótico da solução de cultivo, podendo também ocasionar toxicidade iônica, desequilíbrios nutricionais ou ambos, devido à acumulação excessiva de certos íons nos tecidos vegetais (BOSCO, M. R de. et al., 2009).

O decréscimo na germinação de sementes submetidas à restrição hídrica também reside no fato de que, nessas condições, ocorre um prolongamento da fase estacionária do processo de embebição, devido à redução na atividade enzimática, resultando em menor desenvolvimento meristemático e, consequentemente, em atraso na protrusão da radícula (FARIAS et al., 2009).

\section{Metodologia}

O experimento foi conduzido no laboratório de biologia do Centro de Ciências Agrárias e da Biodiversidade, da universidade Federal do Cariri, situada no município de Crato - CE, no período de 27 de maio a 02 de junho de 2017. Antes de iniciar o experimento foi feita uma seleção das sementes selecionando as sementes inteiras.

A indução do estresse salino foi realizada com soluções de cloreto de sódio $(\mathrm{NaCl})$ compondo quatro tratamentos com quatro repetições cada, sendo os níveis de potencial osmótico de 0,$0 ;-0,6 ;-1,2 ; \mathrm{e}-1,8 \mathrm{Mpa}$. As sementes foram dispostas entre folhas de papel germitest esterilizadas e embebidas com as soluções dos diferentes potenciais osmóticos, que em seguida foram colocados dentro de sacos plásticos e acondicionados em câmara de germinação do tipo B.O.D, a $30^{\circ}$ C. Após 10 dias de germinação, foram analisadas a porcentagem de germinação (plântulas normais), plântulas anormais e sementes mortas/não germinadas.

Juntamente com o teste de germinação foram computadas diariamente as sementes germinadas para cálculo do Índice de Velocidade de Germinação (IVG), com emprego da fórmula proposta por Maguire (1962).IVG $=\mathbf{E}_{1} / \mathbf{N}_{1}+\mathbf{E}_{2} / \mathbf{N}_{2}+\ldots+\mathbf{E}_{\mathbf{m}} / \mathbf{N}_{\mathbf{n}}$

Onde: $E_{1}, E_{2}, \ldots, E_{m}=n^{o}$ de plântulas emergidas, computadas na primeira, segunda, ..., última contagem $\mathrm{N}_{1}, \mathrm{~N}_{2}, \ldots, \mathrm{N}_{\mathrm{n}}=\mathrm{n}^{\mathrm{o}}$ de dias de semeadura à primeira, segunda, ..., última contagem

Para obtenção do Tempo Médio de Germinação (TM), Frequência Relativa de Germinação (Fr) e Sincronização da germinação (U) utilizou-se as fórmulas propostas por Labouriau (1983) como segue: $\mathbf{T M}=(\Sigma \mathbf{n i t i}) / \Sigma \mathbf{n i}$

Onde: TM= tempo médio de germinação; ni= número de sementes germinadas por dia; ti= tempo de incubação (dias). 


\section{$U=-\Sigma$ fi $\log _{2} \mathbf{f i}$}

Onde: $U=$ sincronização de germinação; $f i=$ freqüência relativa degerminação; $\log _{2}=\operatorname{logaritmo}$ na base 2 .

O delineamento utilizado foi o inteiramente casualizado com quatro tratamentos constando de quatro repetições, cada repetição com 25 sementes. Os dados obtidos foram submetidos a análise de variância, as médias foram comparadas pelo teste de Tukey a $5 \%$ de probabilidade e também por análise de regressão.

\section{Resultados e Discussões}

Os dados obtidos para as diferentes concentrações de sais apresentou efeito significativo sobre a germinação (plântulas normais), plântulas anormais e sementes mortas/não germinadas (Tabela 1).Entre as concentrações salinas, foi observado que a crotalaria obteve o melhor vigor germinativo na concentração de $0,0 \mathrm{Mpa}$. Em contrapartida, a maior porcentagem de plântulas anormais foi observado no potencial osmótico de -1,2 Mpa. Para plantas mortas não houve diferença entre as concentrações.

Tabela 1 -Porcentagens de germinação (plântulas normais), plântulas anormais e sementes mortas/não germinadas. Fonte: própria

\begin{tabular}{cccc}
\hline Tratamentos & Normal & Anormal & Mortas \\
\hline 0 & $73 \mathrm{~A}$ & $17 \mathrm{~A}$ & $10 \mathrm{~A}$ \\
0,6 & $8 \mathrm{~B}$ & $79 \mathrm{~B}$ & $11 \mathrm{~A}$ \\
1,2 & $8 \mathrm{~B}$ & $82 \mathrm{~B}$ & $18 \mathrm{~A}$ \\
1,8 & $4 \mathrm{~B}$ & $86 \mathrm{~B}$ & $10 \mathrm{~A}$ \\
\hline
\end{tabular}

*Médias seguidas pela mesma letra maiúscula na coluna não diferenciam entre si pelo teste de Tukey a $5 \%$ de probabilidade

Os dados mostrados na Tabela 1 demonstraram que para as duas maiores concentrações de cloreto de sódio houve altos índices de porcentagens de plântulas anormais pois o potencial osmótico negativo prejudicou o desenvolvimento inicial dessas plântulas, apresentando má formação do sistema radicular, em sementes mortas não houve diferença significativa, entretanto o potencial -1,2 Mpa obteve maior porcentagem em relação as demais concentrações de $\mathrm{NaCl}$.

É possível observar que os resultados obtidos de índice de velocidade de germinação (IVG) que a concentração de 0,0 MPa teve melhor índice de germinação não houve diferença significativa entre as demais concentrações, no tempo médio de germinação (TM) a concentração que obteve 
melhor resultado foi a de 0,0 MPa e a sincronia de germinação(U) não houve diferença estatística nas concentrações -0,6 e -1,2 MPa, sendo o melhor resultado na concentração 0,0 MPa.

O índice de velocidade de germinação(IVG), sofreu efeitos significativos na concentração de 0,0 MPa (Gráfico 4). Foi observado que o aumento na concentração salina reduziu a velocidade de germinação. Essa diminuição da velocidade de germinação também foi observada por NOBRE et al. (2010), pois o aumento da concentração de $\mathrm{NaCl}$ na solução do solo, tenha contribuído negativamente sobre a absorção de água pelas plantas de girassol. O tempo médio de germinação (TM)sofreu efeitos significativos nas concentrações de -1,2 e - 0,6 MPa, tendo maior número de plântulas com tempo de germinação menor em relação as demais concentrações, entretanto o resultado menos satisfatório ocorreu na concentração 0,0 $\mathrm{MPa}$ (Gráfico 5). A sincronia de germinação (U) sofreu efeitos significativos na concentração de -0,6 e -1,2 MPa (Gráfico 6).

Gráfico 4 - Efeitos no IVG em diferentes concentrações de sal. Fonte: própria

$$
\begin{gathered}
y=-2,2813 x^{2}+5,1329 x+7,9947 \\
R^{2}=0,9763
\end{gathered}
$$

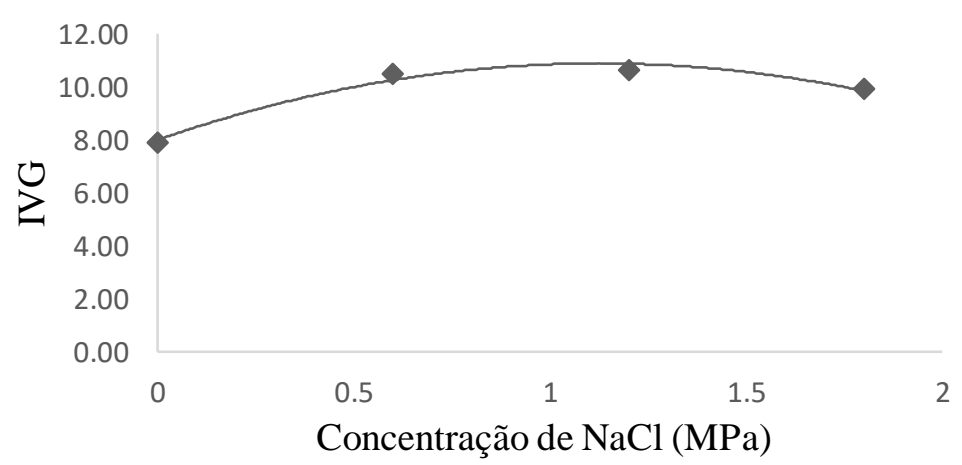

Gráfico 5 - Efeitos no TM em diferentes concentrações de sal. Fonte: Própria

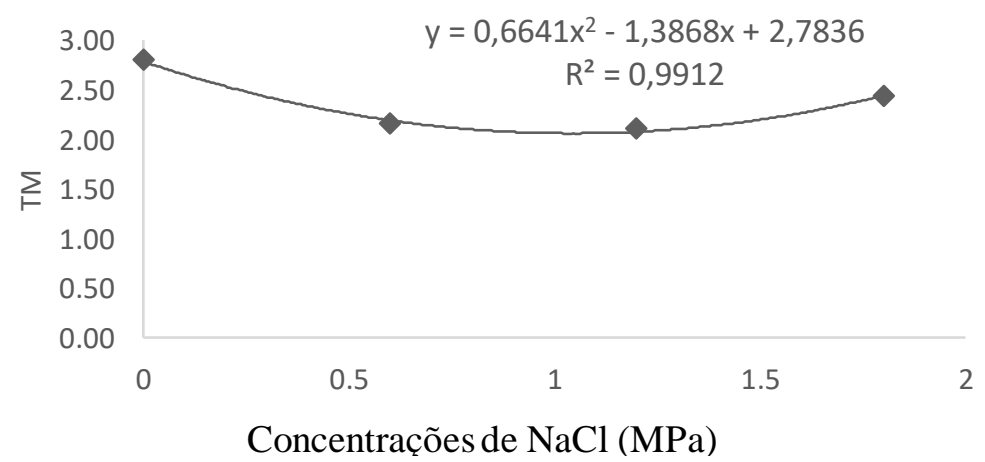


Gráfico 6 - Efeitos no U em diferentes concentrações de sal. Fonte: Própria

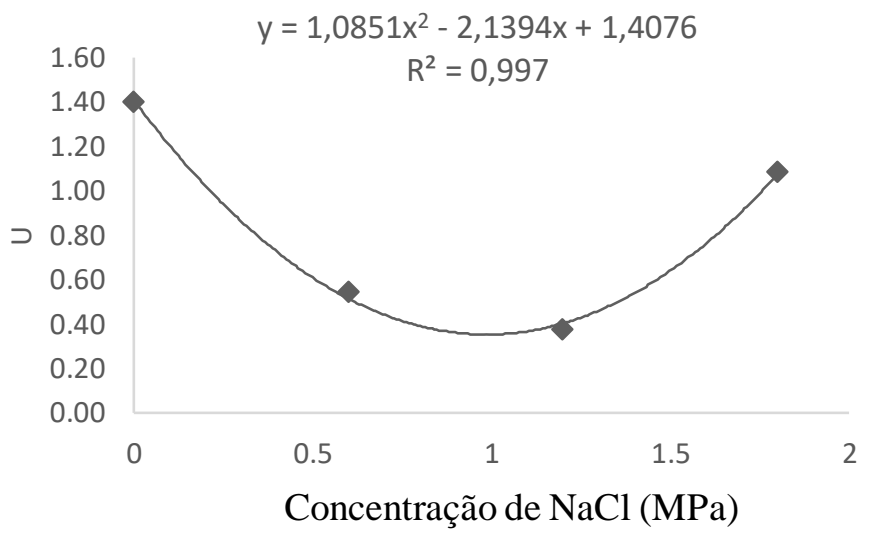

\section{Conclusões}

Com isso conclui-se que quanto mais negativo o potencial osmótico proporcionado pelo cloreto de sódio, menor foi a germinação e o vigor das sementes.

\section{Referências}

BOSCO, M. R de.; OLIVEIRA, A. B de.; HERNANDEZ, F. F. F.; LACERDA, C.F de.Influência do estresse salino na composição mineral da berinjela. Revista Ciência Agronômica, v. 40, n. 2, p.157-164, abr-jun, 2009.

FARIAS, S. G. G.; FREIRE, A. L de. O.; SANTOS, D. R D dos,; BAKKE, I.A.; SILVA, R. B e. Efeitos dos estresses hídrico e salino na germinação de sementes de gliricidia [gliricidiasepium (jacq.) Steud.]. Revista Caatinga, Mossoró, v.22, n.4, p.152-157, out.-dez. 2009.

NOBRE, R. G.; GHEYI, H. R.; CORREIA, K. G.; SOARES, F.A.L.; ANDRADE, L. O de.Crescimento e floração do girassol sob estresse salino e adubação nitrogenada.Revista Ciência Agronômica, v. 41, n. 3, p. 358-365, jul-set, 2010.

NUNES, A. da S.; LOURENÇÃO, A. L. F.; PEZARICO, C. R.; SCALON, S. de P. Q.; GONÇALVES, M. C.Fontes e níveis de salinidade na germinação de sementes de CrotalariaJuncea $L$. Ciênc. agrotec., Lavras, v. 33, n. 3, p. 753-757, maio/jun., 2009.

PINHEIRO, D.T. Estresse Salino no Potencial Fisiológico de Sementes e no Desenvolvimento Vegetativo de Melão. Viçosa: UFV, 2015 P 654. Dissertação de Mestrado - Programa de PósGraduação em Fitotecnia. Universidades Federal de Viçosa, Viçosa, 2015. 